\title{
Optoelectronic Properties and the Electrical Stability of Ga-Doped ZnO Thin Films Prepared via Radio Frequency Sputtering
}

\author{
Shien-Uang Jen ${ }^{1,2}$, Hui Sun ${ }^{3}$, Hai-Pang Chiang ${ }^{2}$, Sheng-Chi Chen ${ }^{4,5, *}$, Jian-Yu Chen ${ }^{2,4}$ \\ and Xin Wang ${ }^{3}$ \\ 1 Institute of Physics, Academia Sinica, Taipei 115, Taiwan; physjen@gate.sinica.edu.tw \\ 2 Institute of Optoelectronic Science, National Taiwan Ocean University, Keelung 202, Taiwan; \\ hpchiang@ntou.edu.tw (H.-P.C.); alexunh@126.com (J.-Y.C.) \\ 3 Institute of Materials Science and Engineering, Ocean University of China, 238 Songling Road, \\ Qingdao 266100, China; sunhuichn@hotmail.com (H.S.); wangxinhd@ouc.edu.cn (X.W.) \\ 4 Department of Materials Engineering and Center for Thin Film Technologies and Applications, \\ Ming Chi University of Technology, Taipei 243, Taiwan \\ 5 Department of Electronic Engineering, Chang Gung University, Taoyuan 333, Taiwan \\ * Correspondence: chensc@mail.mcut.edu.tw; Tel.: +886-2-2908-9899 (ext. 4679) \\ Academic Editor: Andrea Li Bassi
}

Received: 26 October 2016; Accepted: 29 November 2016; Published: 6 December 2016

\begin{abstract}
In this work, Ga-doped $\mathrm{ZnO}$ (GZO) thin films were deposited via radio frequency sputtering at room temperature. The influence of the Ga content on the film's optoelectronic properties as well as the film's electrical stability were investigated. The results showed that the film's crystallinity degraded with increasing Ga content. The film's conductivity was first enhanced due to the replacement of $\mathrm{Zn}^{2+}$ by $\mathrm{Ga}^{3+}$ before decreasing due to the separation of neutralized gallium atoms from the $\mathrm{ZnO}$ lattice. When the Ga content increased to 15.52 at \%, the film's conductivity improved again. Furthermore, all films presented an average transmittance exceeding $80 \%$ in the visible region. Regarding the film's electrical stability, GZO thermally treated below $200^{\circ} \mathrm{C}$ exhibited no significant deterioration in electrical properties, but such treatment over $200{ }^{\circ} \mathrm{C}$ greatly reduced the film's conductivity. In normal atmospheric conditions, the conductivity of GZO films remained very stable at ambient temperature for more than 240 days.
\end{abstract}

Keywords: Ga-doped $\mathrm{ZnO}$ (GZO) thin films; optoelectronic properties; rf sputtering; electrical stability

\section{Introduction}

Transparent conductive oxides (TCOs) have been widely studied in the last few decades due to their high electrical conductivity and good optical transmittance in the visible light region. They can be used in fields such as solar cells, flat-panel displays, light emitting diodes, and smart windows [1-5]. In particular, Sn-doped $\mathrm{In}_{2} \mathrm{O}_{3}$ (ITO) films present outstanding optoelectronic performance and have been widely used in various commercial domains [6-8]. However, due to the toxicity and limited availability of indium, further applications of ITO are restricted, so novel alternative materials must be developed [9,10]. ZnO-based oxides are considered one of the most promising transparent conductive oxides due to their low production cost, non-toxicity, low growth temperature, and high adaptability to various substrates [11-16]. Nevertheless, their practical feasibility is strongly restricted by the poor electrical properties of intrinsic $\mathrm{ZnO}$ thin films. In order to overcome this drawback, many studies have attempted to improve the performance of $\mathrm{ZnO}$. One approach is to enhance the electrical and optical properties of $\mathrm{ZnO}$ thin films by trivalent Ga doping [17-21]. 
In this work, Ga-doped $\mathrm{ZnO}(\mathrm{GZO})$ thin films were prepared via radio frequency (rf) sputtering on $\mathrm{ZnO}$ and $\mathrm{Ga}_{2} \mathrm{O}_{3}$ targets. The influences of varying the sputtering power applied to the $\mathrm{Ga}_{2} \mathrm{O}_{3}$ target on the composition and optoelectronic properties of the films were investigated. The film's thermal and time stabilities are also discussed.

\section{Results and Discussion}

The influence of the sputtering power applied to the $\mathrm{Ga}_{2} \mathrm{O}_{3}$ target $\left(P_{\mathrm{Ga} 2 \mathrm{O} 3}\right)$ on the variation in Ga content in the films was first investigated. The results are shown in Figure 1. With increases in $P_{\mathrm{Ga} 2 \mathrm{O} 3}$, Ga content initially increased slightly $\left(P_{\mathrm{Ga} 2 \mathrm{O} 3}<20 \mathrm{~W}\right)$ before rising significantly as $P_{\mathrm{Ga} 2 \mathrm{O} 3}$ rose above $20 \mathrm{~W}$. The actual Ga content of the films with various $P_{\mathrm{Ga} 2 \mathrm{O} 3}$ is given in the inset table. $\mathrm{ZnO}$ with 0.60 at $\%$ Ga thin film was obtained when $P_{\mathrm{Ga} 2 \mathrm{O} 3}$ was fixed at $20 \mathrm{~W}$. When $P_{\mathrm{Ga} 2 \mathrm{O} 3}$ was above $30 \mathrm{~W}, \mathrm{Ga}$ content increased to more than 4.29 at \%. As reported by H. Gomez [22] and R. Wang [23], the solubility limit of $\mathrm{Ga}$ in $\mathrm{ZnO}$ is around 2-3 at \% at room temperature. If more $\mathrm{Ga}$ is introduced into $\mathrm{ZnO}$ thin film, the redundant gallium atoms will segregate from the $\mathrm{ZnO}$ lattice and form neutralized gallium species in the grain boundaries of $\mathrm{ZnO}$.

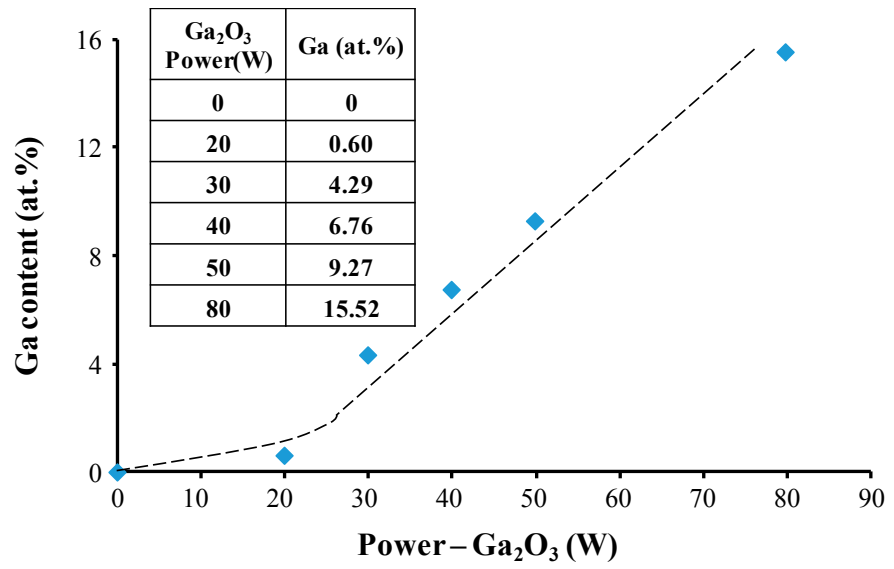

Figure 1. Ga content in $\mathrm{ZnO}$ thin films as a function of the sputtering power applied on the $\mathrm{Ga}_{2} \mathrm{O}_{3}$ target.

The X-ray diffraction patterns of the $\mathrm{ZnO}$ thin films with varying amounts of Ga are shown in Figure 2. When the doping content of Ga was about 0.6 at \%, no obvious peak shift was observed. Even though the ionic radius of $\mathrm{Ga}^{3+}(0.062 \mathrm{~nm})$ is smaller than that of $\mathrm{Zn}^{2+}(0.074 \mathrm{~nm})$ [24], the amount of $\mathrm{Zn}^{2+}$ cations replaced by $\mathrm{Ga}^{3+}$ cations was at a very low level, so the contraction in lattice parameters was not considerable. However, when the content of $\mathrm{Ga}^{3+}$ cations exceeded 4.29 at $\%$, the $\mathrm{ZnO}$ diffraction peaks moved to lower diffraction angles. This movement became more pronounced with the rise in $\mathrm{Ga}$ content owing to redundant $\mathrm{Ga}$ atoms entering into the $\mathrm{ZnO}$ lattice and forming $\mathrm{Ga}$ interstitial $\left(\mathrm{Ga}_{i}\right)$ defects, which enlarged the lattice parameters of $\mathrm{ZnO}$. Moreover, as the extrinsic defects of $\left(\mathrm{GaZn}_{\mathrm{Zn}}\right)$ (the substitution of $\mathrm{Zn}$ by $\left.\mathrm{Ga}\right)$, and $\left(\mathrm{Ga}_{i}\right)$ were introduced into the $\mathrm{ZnO}$ films, the films' crystallinity degraded as the Ga content increased.

The degradation of the film's crystallinity with increasing Ga content was revealed by TEM observation (Figure 3$)$. The crystallinity of GZO films with more gallium $\left(P_{\mathrm{Ga} 2 \mathrm{O} 3}=50 \mathrm{~W}\right)$ was found to be inferior to those with less gallium $\left(P_{\mathrm{Ga} 2 \mathrm{O} 3}=30 \mathrm{~W}\right)$. Some amorphous domains (highlighted by red dotted lines) embedded in the crystallized $\mathrm{ZnO}$ are visible in Figure $3 b_{1}$, but none can be found in Figure $3 \mathrm{a}_{1}$. Additionally, in comparing the selected area electron diffraction (SAED) patterns of these two films, the conversion of the diffraction spots (Figure $\left.3 a_{2}\right)$ to the diffraction rings $\left(\right.$ Figure $\left.3 b_{2}\right)$ indicated an obvious reduction in grain size, which degraded the film's crystallinity. 


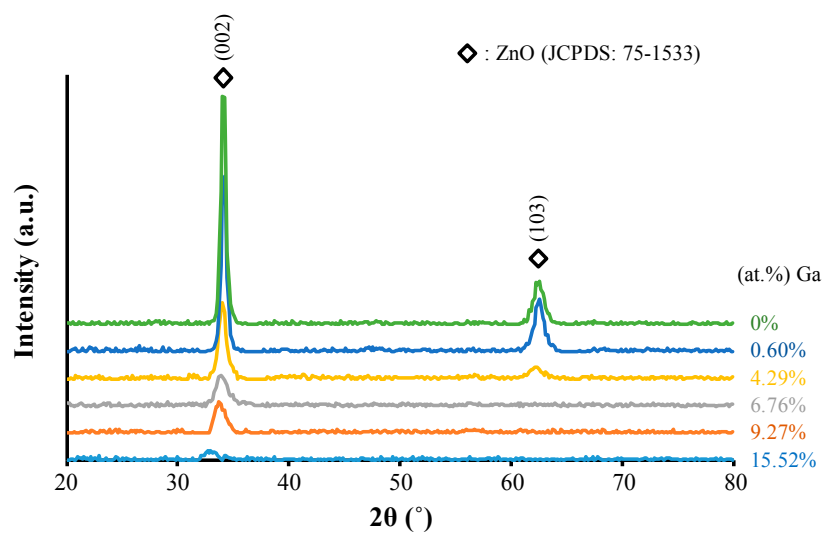

Figure 2. X-ray diffraction (XRD) patterns of $\mathrm{ZnO}$ thin films with varying amounts of Ga.
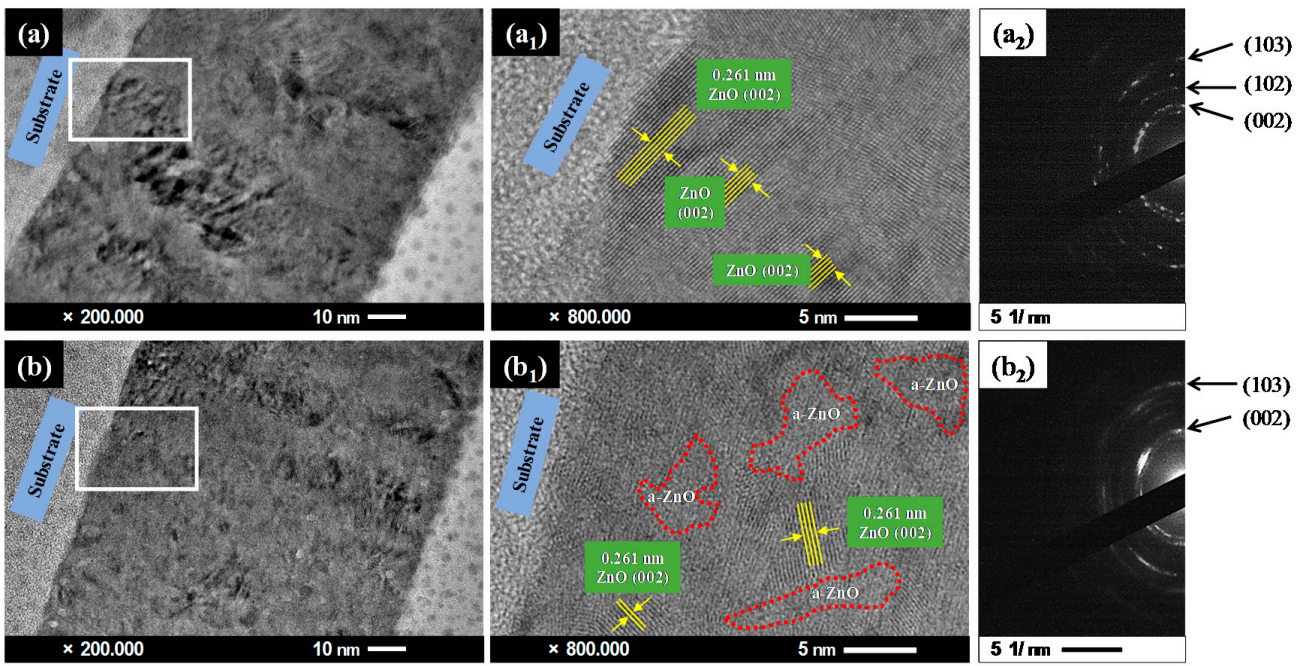

Figure 3. TEM observation and the corresponding high-resolution TEM images of Ga-doped $\mathrm{ZnO}$ (GZO) films deposited with $\mathrm{Ga}_{2} \mathrm{O}_{3}$ powers of $30 \mathrm{~W}\left(\mathbf{a}_{,} \mathbf{a}_{\mathbf{1}}\right)$ and $50 \mathrm{~W}\left(\mathbf{b}, \mathbf{b}_{\mathbf{1}}\right)$, and their electron diffraction patterns: $30 \mathrm{~W}\left(\mathbf{a}_{2}\right)$ and $50 \mathrm{~W}\left(\mathbf{b}_{\mathbf{2}}\right)$.

The film's conductivity as a function of Ga content in $\mathrm{ZnO}$ films is shown in Figure 4. The conductivity of the film without Ga doping was too low to be detected under our experimental conditions. After the Ga doping of $\mathrm{ZnO}$, the film's conductivity significantly improved when the doping concentration was less than 4.29 at \%, a range (Zone 1) in which $\mathrm{Zn}^{2+}$ cations were effectively replaced by $\mathrm{Ga}^{3+}$ cations. However, this improvement of the film's conductivity disappeared when the $\mathrm{Ga}^{3+}$ content increased to a range of 4.29-9.27 at \% (Zone 2), due mainly to the Ga content exceeding its solubility in $\mathrm{ZnO}$ and neutralized gallium atoms separating from the $\mathrm{ZnO}$ lattice. These neutralized species could not contribute to the generation of free electrons and enhanced the scattering effect of the carriers in $\mathrm{ZnO}$ films. Therefore, the film's conductivity declined in this range. Upon a further increase in Ga content to 15.52 at \% (Zone 3), the film's conductivity improved because the neutralized gallium atoms gathered together and formed Ga clusters due to the high Ga doping concentration. Given that the work functions of gallium and intrinsic $\mathrm{ZnO}$ are about $4.2 \mathrm{eV}$ and $4.5 \mathrm{eV}$, respectively [25], ohmic contact occurred between the metallic gallium and n-type $\mathrm{ZnO}$. As a result, the abundant electrons in gallium easily transferred into the $\mathrm{ZnO}$, and the film's conductivity thus increased. 


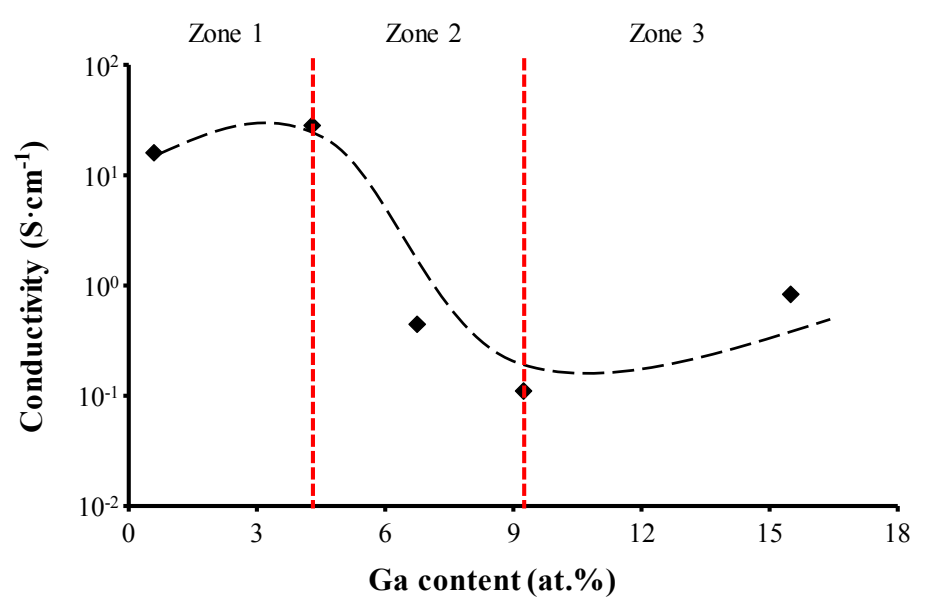

Figure 4. The variation in film conductivity as a function of Ga content in $\mathrm{ZnO}$ films.

The variation in the carrier concentration in the films with increasing Ga concentration was analyzed via Hall measurement, and the results are shown in Figure 5. The carrier concentration exhibited a trend similar to that of the film's conductivity and revealed the formation and development of neutralized gallium species. When the Ga content was relatively low (Zone 1), most gallium atoms were ionized and replaced $\mathrm{Zn}^{2+}$ cations. Free electrons were derived from this replacement. Thus, the carrier concentration increased with rising gallium content. In Zone 2, the carrier concentration decreased due to an increasing number of gallium atoms separating from the $\mathrm{ZnO}$ lattice and forming neutral defects, which did not contribute to the generation of free electrons. Furthermore, the intrinsic donor defects of oxygen vacancies could be occupied by Ga atoms, which reduced the carrier concentration. In Zone 3, gallium atoms gathered into clusters, and more electrons could easily transfer from gallium clusters to $\mathrm{ZnO}$ films. Thus, the carrier concentration increased.

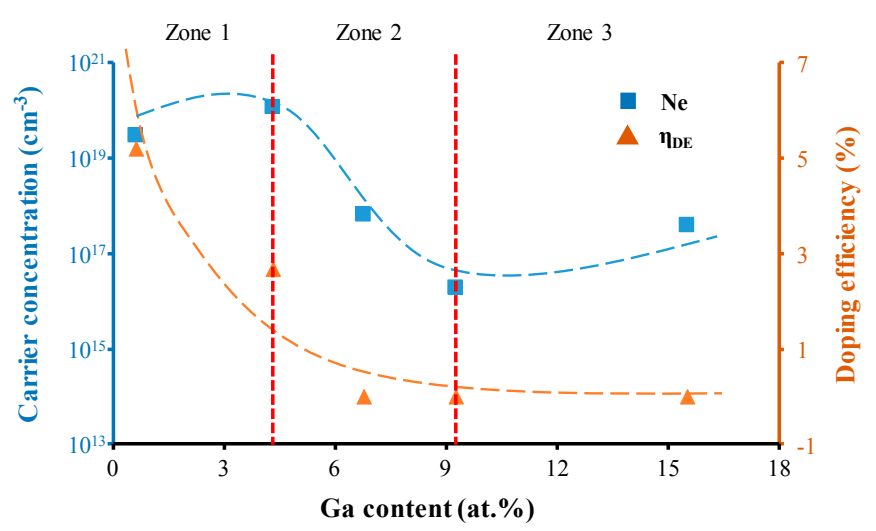

Figure 5. The variation in carrier concentration Ne and doping efficiency $\eta_{\mathrm{DE}}$ as a function of Ga content (the bulk $\mathrm{ZnO}$ density of $5.606 \mathrm{~g} / \mathrm{cm}^{3}$ was used to estimate $\eta_{\mathrm{DE}}$ ).

In order to understand the effective doping amount and the electrical activity of gallium in the $\mathrm{ZnO}$ films, the doping efficiency ( $\eta_{\mathrm{DE}}$ ) of $\mathrm{Ga}^{3+}$ cations in $\mathrm{ZnO}$ was also investigated (Figure 5). $\eta_{\mathrm{DE}}$ is defined as the ratio of the carrier concentration to the atomic ratio of $\mathrm{Ga} /(\mathrm{Ga}+\mathrm{Zn})$, where the free electrons in $\mathrm{ZnO}$ films are mainly considered to be created by Ga substitution. As shown in Figure 5, the doping efficiency decreased with increasing gallium content, suggesting that more gallium atoms separated from the $\mathrm{ZnO}$ as gallium content increased.

The film's transmittance is shown in Figure 6. Regardless of the Ga content of the $\mathrm{ZnO}$, the films presented high transmittance in the visible region $(400 \mathrm{~nm}$ to $800 \mathrm{~nm})$. Their average transmittance 
was always above $80 \%$. When the Ga content was increased from 0 at $\%$ to 6.76 at $\%$, the number of defects, such as $\left(\mathrm{Ga}_{\mathrm{Zn}}\right)$ and $\left(\mathrm{Ga}_{i}\right)$, and $\mathrm{Ga}$ clusters increased, and the light scattering by these defects and clusters was enhanced. Hence, a slight decrease in the film's transmittance was observed in this region. With further increases in Ga content, gallium clusters gathered together, increasing in size while decreasing in number. The film's transmittance then improved. In addition, with increases in Ga content, blue shifting of the absorption edge was observed, corresponding to the expansion of the film's band gap. According to Vagard's law mentioned in [26], because the band gap of $\mathrm{Ga}_{2} \mathrm{O}_{3}$ is about $4.9 \mathrm{eV}$ larger than that of $\mathrm{ZnO}$, the band gap of $\mathrm{Zn}_{1-x} \mathrm{Ga}_{x} \mathrm{O}$ films should increase linearly as the Ga doping amount increases.

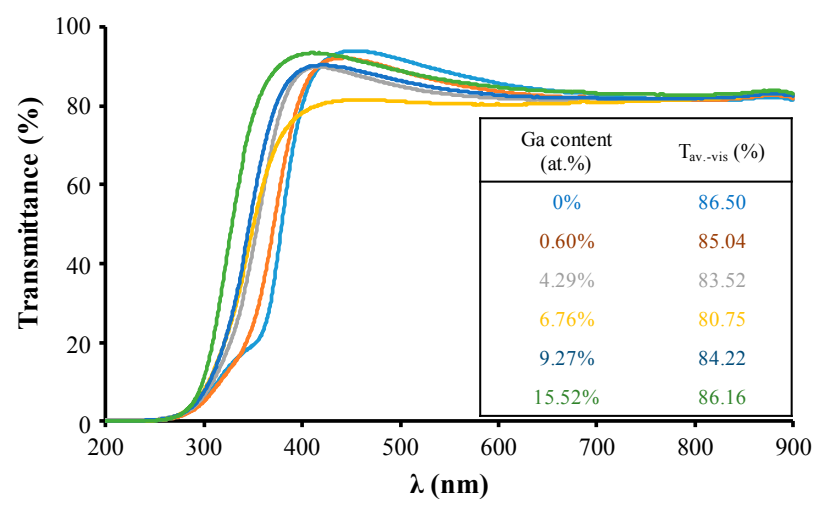

Figure 6. The variation in film transmittance as a function of Ga content in $\mathrm{ZnO}$ films.

The film's electrical thermal stability is shown in Figure 7. A $\mathrm{ZnO}$ film with 4.29 at \% Ga was annealed at various temperatures under normal atmospheric conditions. When the annealing temperature was below $200^{\circ} \mathrm{C}$, the film's conductivity was slightly degraded with increasing annealing temperature because the oxygen vacancies $\left(V_{\mathrm{O}}\right)$ in the $\mathrm{ZnO}$ film were occupied by oxygen in oxygenated conditions. As reported by A.F. Kohan [27], oxygen vacancies, as the most important intrinsic donor defect, are favorable to the film's n-type conductivity. Therefore, with the reduction in the number of oxygen vacancies, the carrier concentration also decreased. In addition, due to the reduction in the number of $V_{\mathrm{O}}$ defects, the carrier scattering by these defects was restricted, so the carrier mobility improved.

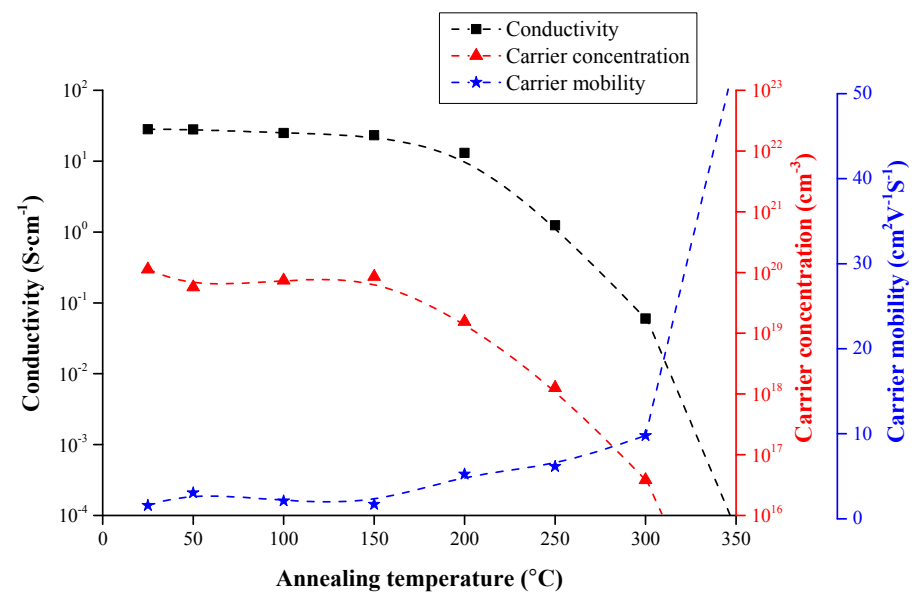

Figure 7. The electrical thermal stability of the $\mathrm{ZnO}$ film with 4.29 at \% Ga under normal atmospheric conditions. 
The melting point of gallium is only around $29.7^{\circ} \mathrm{C}$ [28], and the partial pressure of indium atoms on the surface of the film is much lower than the saturated vapor pressure of indium. Therefore, when the annealing temperature exceeded $200{ }^{\circ} \mathrm{C}$, the neutral gallium atoms that could not replace $\mathrm{Zn}$ cations obtained sufficient energy to migrate to the surface of the $\mathrm{ZnO}$ film, where they easily reacted with oxygen and formed insulating oxides. Hence, the carrier concentration and conductivity significantly dropped, and the carrier mobility increased. When the annealing temperature was higher than $300^{\circ} \mathrm{C}$, the film became completely insulating.

The film's electrical time stability is given in Figure 8. The $\mathrm{ZnO}$ film with 4.29 at \% Ga was placed in normal atmospheric conditions at ambient temperature for more than 240 days. With prolonged analysis time, the film's electrical properties remained almost unchanged. In other words, the occupation of oxygen vacancies by oxygen atoms in oxygenated conditions could be activated only at high temperatures. Furthermore, gallium atoms cannot migrate in a $\mathrm{ZnO}$ lattice spontaneously at room temperature. Accordingly, the $\mathrm{ZnO} / \mathrm{Ga}$ films presented satisfactory time stability.

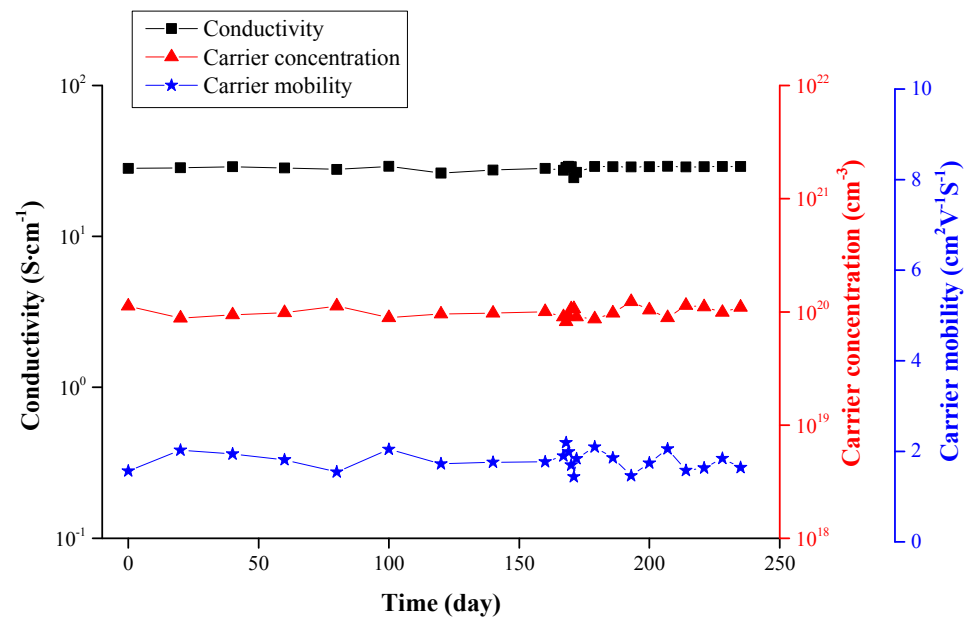

Figure 8. The electrical time stability of the $\mathrm{ZnO}$ film with 4.29 at $\% \mathrm{Ga}$ at ambient temperature.

\section{Materials and Methods}

\subsection{Deposition Parameters}

Ga-doped $\mathrm{ZnO}$ (GZO) thin films with a thickness of about $100 \mathrm{~nm}$ were deposited on Corning $1737 \mathrm{~F}$ glass substrates at room temperature via rf sputtering. The substrate holder rotation rate was about $10 \mathrm{rpm}$. Pure Ar was used as the working gas, and the working pressure was about 0.67 Pa. The sputtering power applied to the $\mathrm{ZnO}$ target (purity $99.95 \%$, diameter $2.54 \mathrm{~cm}$ ) was fixed at $80 \mathrm{~W}$, while the sputtering power applied to the $\mathrm{Ga}_{2} \mathrm{O}_{3}$ target (purity $99.95 \%$, diameter $2.54 \mathrm{~cm}$ ) varied from 0 to $80 \mathrm{~W}$. The power densities applied on $\mathrm{ZnO}$ and $\mathrm{Ga}_{2} \mathrm{O}_{3}$ targets are given in Tables 1 and 2. Other sputtering parameters maintained during the deposition of GZO thin films are shown in Table 3.

Table 1. The power densities applied on $\mathrm{ZnO}$ target.

\begin{tabular}{cc}
\hline Power $(W)$ & Power Density $\left(W / \mathbf{c m}^{2}\right)$ \\
\hline 80 & 3.95 \\
\hline
\end{tabular}


Table 2. The power densities applied on $\mathrm{Ga}_{2} \mathrm{O}_{3}$ target.

\begin{tabular}{cc}
\hline Power $(\mathbf{W})$ & Power Density $\left(\mathrm{W} / \mathrm{cm}^{\mathbf{2}}\right)$ \\
\hline 0 & 0 \\
20 & 0.99 \\
30 & 1.48 \\
40 & 1.97 \\
50 & 2.47 \\
80 & 3.95 \\
\hline
\end{tabular}

Table 3. Sputtering parameters maintained during the deposition of GZO thin films.

\begin{tabular}{|c|c|}
\hline Parameter & Values \\
\hline Background pressure (Pa) & $<6.7 \times 10^{-4}$ \\
\hline Working pressure $(\mathrm{Pa})$ & 0.67 \\
\hline Films thickness (nm) & 100 \\
\hline Rotation speed (rpm) & 10 \\
\hline Substrate & Glass/Silicon \\
\hline Power $(W)$ & $\begin{array}{c}\mathrm{ZnO} \\
\mathrm{Ga}_{2} \mathrm{O}_{3}\end{array}$ \\
\hline
\end{tabular}

\subsection{Materials Characterizations}

The thickness of the films was measured with a surface profilometer (Surfcoder SE-2300, Kosaka Laboratory Ltd., Tokyo, Japan). The composition of the films was detected with an electron probe X-ray microanalyzer (EPMA, JXA-8900R, JOEL, Tokyo, Japan). The phase structures of the films were analyzed with an X-ray diffractometer (XRD, X'Pert PRO MRD, Philips PANalytical, Almelo, The Netherlands) using the thin film mode with an incidence angle of $1^{\circ}$. Hall effect analysis (AHM-800B, Agilent Technologies, Santa Clara, CA, USA) with van der Pauw's configuration was employed to investigate the electrical properties of the films. Finally, the transmittance of the films was measured with a UV-Vis spectrophotometer (JASCO-V650, JASCO, Tokyo, Japan).

\section{Conclusions}

GZO films were deposited via rf sputtering. The optoelectronic properties of the films as a function of $\mathrm{Ga}$ content were investigated. It was found that, when the gallium content was near 4.29 at \%, $\mathrm{ZnO} / \mathrm{Ga}$ films possess optimal electrical properties. All such $\mathrm{ZnO}$ films present high transmittance in the visible region, regardless of gallium content. In addition, due to the occupation of oxygen vacancies by oxygen atoms and the migration of gallium atoms in ZnO film, the film's electrical properties are degraded under high temperatures in oxygenated conditions. However, this degradation was not observed in the time stability examination. This result suggests that $\mathrm{ZnO} / \mathrm{Ga}$ films can withstand long-term loads at ambient temperatures but are not suitable for applications in high-temperature environments.

Acknowledgments: We gratefully acknowledge the National Natural Science Foundation of China (No. 51172217) and Ministry of Science and Technology of Taiwan (No. 103-2221-E-131-004) for their financial support. We also thank H.C. Lin and C.Y. Kao of the Instrumentation Center, National Taiwan University, for EPMA experiments.

Author Contributions: Sheng-Chi Chen and Shien-Uang Jen conceived and designed the experiments; Jian-Yu Chen performed the experiments; Hui Sun and Xin Wang analyzed the data; Hai-Pang Chiang contributed reagents/materials/analysis tools; Hui Sun wrote the paper.

Conflicts of Interest: The authors declare no conflict of interest. 


\section{References}

1. Chen, X.L.; Liu, J.M.; Ni, J.; Zhao, Y.; Zhang, X.D. Wide-spectrum Mg and Ga co-doped ZnO TCO thin films for solar cellsgrown via magnetron sputtering with $\mathrm{H}_{2}$ introduction. Appl. Surf. Sci. 2015, 328, 193-197. [CrossRef]

2. Kim, S.I.; Cho, S.H.; Choi, S.R.; Oh, M.C.; Jang, J.H.; Song, P.K. Crystallization and electrical properties of ITO: Ce thin films for flat panel display applications. Thin Solid Films 2009, 5107, 4061-4064. [CrossRef]

3. Ko, Y.D.; kim, K.C.; Kim, Y.S. Effects of substrate temperature on the Ga-doped ZnO films as an anode material of organic light emitting diodes. Superlattices Microstruct. 2012, 51, 933-941. [CrossRef]

4. Bartens, R.; Jelle, B.P.; Gustavsen, A. Properties, requirements and possibilities of smart windows for dynamic daylight and solar energy control in buildings: A state-of-the-art review. Sol. Energy Mater. Sol. Cells 2010, 94, 87-105. [CrossRef]

5. Domaradzki, J. Perspectives of development of TCO and TOS thin films based on (Ti-Cu) oxide composites. Surf. Coat. Technol. 2016, 290, 28-33. [CrossRef]

6. Sibin, K.P.; Swain, N.; Chowdhury, P.; Dey, A.; Sridhara, N.; Shashikala, H.D.; Sharma, A.K.; Barshilia, H.C. Optical and electrical properties of ITO thin films sputtered on flexible FEP substrate as passive thermal control system for space applications. Sol. Energy Mater. Sol. Cells 2016, 145, 314-322. [CrossRef]

7. Yu, S.H.; Yang, W.H.; Li, L.X.; Zhang, W.F. Improved chemical stability of ITO transparent anodes with a $\mathrm{SnO} 2$ buffer layer for organic solar cells. Sol. Energy Mater. Sol. Cells 2016, 144, 652-656. [CrossRef]

8. Li, Y.P.; Sun, J. The modification of electrical properties of $\mathrm{Au} / \mathrm{n}-\mathrm{Hg}_{3} \mathrm{In}_{2} \mathrm{Te}_{6}$ Schottky contact by the introduction of ITO interlayer. Curr. Appl. Phys. 2016, 16, 623-627. [CrossRef]

9. Aleksandrova, M.; Kurtev, N.; Videkov, V.; Tzanova, S.; Schintke, S. Material alternative to ITO for transparent conductive electrode in flexible display and photovoltaic devices. Microelectron. Eng. 2015, 145, 112-116. [CrossRef]

10. Linss, V. Comparison of the large-area reactive sputter processes of $\mathrm{ZnO}: \mathrm{Al}$ and ITO using industrial size rotatable targets. Surf. Coat. Technol. 2016, 290, 43-57. [CrossRef]

11. Tubtimtae, A.; Lee, M.W. ZnO nanorods on undoped and indium-doped ZnO thin films as a TCO layer on nonconductive glass for dye-sensitized solar cells. Superlattices Microstruct. 2012, 52, 987-996. [CrossRef]

12. Chen, S.C.; Wang, C.H.; Sun, H.; Wen, C.K.; Lu, C.F.; Tsai, C.L.; Fu, Y.K.; Chuang, T.H. Microstructures, electrical and magnetic properties of $(\mathrm{Ga}, \mathrm{Co})-\mathrm{ZnO}$ films by radio frequency magnetron co-sputtering. Surf. Coat. Technol. 2016, 303, 203-208. [CrossRef]

13. Jayaraman, V.K.; Alvarez, A.M.; Kuwabara, Y.M.; Koudriavstev, Y.; Amador, M.O. Effect of co-doping concentration on structural, morphological, optical and electrical properties of aluminium and indium co-doped $\mathrm{ZnO}$ thin films deposited by ultrasonic spray pyrolysis. Mater. Sci. Semicond. Process. 2016, 47, 32-36. [CrossRef]

14. Wang, F.H.; Chang, C.L. Effect of substrate temperature on transparent conducting $\mathrm{Al}$ and Fco-doped ZnO thin films prepared by rf magnetron sputtering. Appl. Surf. Sci. 2016, 370, 83-91. [CrossRef]

15. Jin, C.; Narayan, R.; Tiwari, A.; Zhou, H.H.; Kvit, A.; Narayan, J. Epitaxial growth of zinc oxide thin films on silicon. Mater. Sci. Eng. B 2005, 117, 348-354. [CrossRef]

16. Snure, M.; Tiwari, A. Structure, electrical, and optical characterizations of epitaxial films grown on sapphire (0001) substrate. J. Appl. Phys. 2007, 101, 124912. [CrossRef]

17. Jang, C.; Jiang, Q.J.; Lu, J.G.; Ye, Z.Z. Structural, optical and electrical properties of Ga doped ZnO/Cu grid/Ga doped ZnO transparent electrodes. J. Mater. Sci. Technol. 2015, 31, 1108-1110. [CrossRef]

18. Yamada, Y.; Kadowaki, K.; Kikuchi, H.; Funaki, S.; Kubo, S. Positional variation and annealing effect in magnetron sputtered Ga-doped ZnO films. Thin Solid Films 2016, 609, 25-29. [CrossRef]

19. Kim, J.H.; Yer, I.H. Characterization of $\mathrm{ZnO}$ nanowires grown on Ga-doped $\mathrm{ZnO}$ transparent conductive thin films: Effect of deposition temperature of Ga-doped ZnO thin films. Ceram. Int. 2016, 42, 3304-3308. [CrossRef]

20. Bhosle, V.; Tiwari, A.; Narayan, J. Electrical properties of transparent and conducting Ga doped ZnO. J. Appl. Phys. 2006, 100, 033713. [CrossRef]

21. Bhosle, V.; Tiwari, A.; Narayan, J. Metallic conductivity and metal-semiconductor transition in Ga-doped ZnO. Appl. Phys. Lett. 2006, 88, 032106. [CrossRef] 
22. Gomez, H.; Olvera, M.L. Ga-doped ZnO thin films: Effect of deposition temperature, dopant concentration, and vacuum-thermal treatment on the electrical, optical, structural and morphological properties. Mater. Sci. Eng. B 2006, 134, 20-26. [CrossRef]

23. Wang, R.P.; Sleight, A.W. High Conductivity in Gallium-Doped Zinc Oxide Powders. Chem. Mater. 1996, 8, 433-439. [CrossRef]

24. Shannon, R.D. Revised effective ionic radii and systematic studies of interatomic distances in halides and chalcogenides. Acta Cryst. A 1976, 32, 751-767. [CrossRef]

25. Sundaram, K.B.; Khan, A. Work function determination of zinc oxide films. J. Vac. Sci. Technol. A 1997, 15, 428-430. [CrossRef]

26. Snure, M.; Tiwari, A. Band-gap engineering of $\mathrm{Zn}_{1-\mathrm{x}} \mathrm{Ga}_{\mathrm{x}} \mathrm{O}$ nanopowders: Synthesis, structural and optical characterizations. J. Appl. Phys. 2008, 104, 073707. [CrossRef]

27. Kohan, A.F.; Ceder, G.; Morgan, D.; van de Walle, C.G. First-principles study of native point defects in ZnO. Phys. Rev. B 2000, 61, 15019-15027. [CrossRef]

28. Dadzis, K.; Lukin, G.; Meier, D.; Bonisch, P.; Sylla, L.; Patzold, O. Directional melting and solidification of gallium in a traveling magnetic field as a model experiment for silicon processes. J. Cryst. Growth 2016, 445, 90-100. [CrossRef]

(C) 2016 by the authors; licensee MDPI, Basel, Switzerland. This article is an open access article distributed under the terms and conditions of the Creative Commons Attribution (CC-BY) license (http://creativecommons.org/licenses/by/4.0/). 